\title{
Circuit
}

Musiques contemporaines

\section{Foi et création : Java et Bali}

\section{Wilfrid Lemoyne}

Volume 5, numéro 1, 1994

Gilles Tremblay : réflexions

URI : https://id.erudit.org/iderudit/902086ar

DOI : https://doi.org/10.7202/902086ar

Aller au sommaire du numéro

Éditeur(s)

Les Presses de l'Université de Montréal

ISSN

1183-1693 (imprimé)

1488-9692 (numérique)

Découvrir la revue

Citer ce document

Lemoyne, W. (1994). Foi et création : Java et Bali. Circuit, 5(1), 25-28.

https://doi.org/10.7202/902086ar

Ce document est protégé par la loi sur le droit d'auteur. L'utilisation des services d'Érudit (y compris la reproduction) est assujettie à sa politique d'utilisation que vous pouvez consulter en ligne.

https://apropos.erudit.org/fr/usagers/politique-dutilisation/
Cet article est diffusé et préservé par Érudit.

Érudit est un consortium interuniversitaire sans but lucratif composé de l’Université de Montréal, l'Université Laval et l'Université du Québec à Montréal. Il a pour mission la promotion et la valorisation de la recherche. https://www.erudit.org/fr/ 


\section{Java et Bali}

Texte de l'émission « Du monde entier au cour du monde *. Entretien de Wilfrid Lemoyne avec Gilles Tremblay, réalisateur Yves Lapierre, RadioCanada 751211 . C'est avec un poème intitulé U.... Bali et inspiré de son séjour à Bali que Gilles Tremblay ouvre cette émission. Il a noté en exergue: "Vendredi le 18 août 1972. Midi. Après une cérémonie de limage de dent qui avait commencé vers le lever du soleil ».

L'oiseau jaune vient butiner dans les fleurs rouges au feuillage vert.

Cinq sons. Dix lames. Gravité de la main gauche. Volubilité de la droite. Vols des deux. Le mi aigu transperce. Longue tenue des prêtres à gauche. Autre tenue des prêtresses autour des jeunes filles étendues, à droite. La lime gratte la canine animale, nivelle la dent sorcière. Récitatif des longues lames vibrantes, en accélérés. Subitement étouffées par l'attaque, mais en finesse. Jeu en rotations latérales des paumes, en silences inverses des sons. Tracé délicat dans une mosaïque en saillie. Regard lointain, mais présent, profond et extrêmement doux d'un homme qui écoute (d'un Homme).

Grappe-cluster de crachats de bétel dans la poussière.

Face-à-face gauche et droite, masculin-féminin.

Les jeunes gens en demi-cercle élèvent la fleur offrande, mains jointes au-dessus de la tête. Lente harmonie des gestes.

Les paumes ouvertes vers le ciel reçoivent.

Le ciel.

L'eau de la fleur humectée tombe sur chacune des jeunes filles, sur le jeune homme. 
Le crépitement doux, en mosaïque, touche

l'épiderme comme l'eau purificatrice, puis avec

la durée, l'âme même.

J'avais invité un musicien, professeur au Conservatoire et je me trouve tout à coup devant un poète.

Lorsque j'ai entendu cette musique, si extraordinaire, si belle, j'en ai été très bouleversé et enthousiasmé. Comme je n'avais pas d'instrument de musique à ma portée pour déverser le trop plein, je me suis mis à écrire, à évoquer ce qui s'était passé ce matin-là et il en est résulté ce poème.

Comment vous êtes-vous retrouvé à Java et à Bali ? Pourquoi ce voyage?

C'est une vieille passion qui date de l'âge de 17 ou 18 ans, moment où j'ai entendu pour la première fois sur disque Folkways la musique de Bali. Depuis, i'ai lu, regardé des photos sur Bali et j'ai eu envie d'y aller. En 1972, j'ai obtenu une bourse pour aller étudier la musique là-bas. Mais essentiellement parce qu'à Bali, il y a une synthèse, une compréhension de la vie et de l'art, qu'il n'y a pas de mot pour art, mais qu'on se sert du mot VIE pour exprimer ce que veut dire ART.

On parle ici beaucoup d'intégration de l'art, de participation, d'art total. Ces concepts feraient sourire les Balinais qui le font de façon très naturelle.

Le but de mon voyage était de connaître la musique sacrée de ces pays, car j'avais l'intuition qu'il y a quelque chose de commun entre toutes les musiques sacrées, entre le chant bouddhique et le chant grégorien et les musiques sacrées de I'Inde ou de Bali.

Qu'est-ce qui vous intéresse dans cette musique?

Il y a d'abord tout le côté extérieur; ça clignote, ça brille, c'est articulé et rien que pour cela, sur le plan musical, c'est attachant. Mais cela va plus loin. Pour moi, si la musique de Bali n'existait pas, le monde s'écroulerait ; c'est une image pour dire que c'est le peuple au monde qui a peut-être le plus le sens d'un certain rythme fondamental qui rappelle celui des étoiles, des cycles cosmiques et c'est pour cela que je dis que si cela ne tournait plus rond, tout chavirerait.

Expliquez-nous la différence entre la musique de Java et celle de Bali ?

C'est un peu «le pile ou face» d'une même réalité. À Java on trouve également des gamelans mais avec une conception différente; tout est 
beaucoup plus lent et tout se passe dans un raffinement extrême. C'est très impressionniste et ce qui se dégage, c'est la force de conviction que peut avoir la douceur. L'approche temporelle et les cycles rythmiques sont très longs, qui peut aller jusqu'à 4 minutes et demie pour un cycle, c'est un labyrinthe incroyable. $A$ Bali, la musique est beaucoup plus violente, il y a des coups, des chocs et les danses sont plus saccadées.

Vous avez appris à jouer certains instruments?

À Bali, j'ai appris le Gengong, sorte de guimbarde en bois de palme et qui évoque pour moi les insectes.

L'influence de ce voyage se manifestera-telle de façon directe chez vous?

Directe, je ne crois pas. Mais je suis revenu extrêmement troublé. J'avais séjourné quatre mois en Orient. J'avais découvert un monde d'une autre planète, énormément de pauvreté (surtout à Java) et j'étais entré en contact avec une manière de penser tout à fait différente.

Esthétiquement, ça ne m'a jamais intéressé de faire du tourisme musical ou même d'utiliser leurs modes harmoniques; ce serait très artificiel. Mais je suis revenu avec un questionnement fondamental sur le rythme « Apaitou ». «APA ITOU IRAMA \&" (signifiant « qu'est-ce que le rythme $2 »)$ J'espère que cela m'aura donné un peu plus de gravité, de sérieux.

là-bas, on atteint, par le jeu des instruments, une expression d'une puissance extraordinaire par la plus grande douceur; et cette puissance qui vous bouleverse, qui vous fait fondre les os comme dit le psalmiste dans la Bible, est obtenu quelquefois par un coup de gong pianissimo mais joué à un moment privilégié.

Techniquement, ceci invite à une certaine économie, dans l'esprit plutôt que dans la façon dont je réaliserai ceci matériellement. Cette expérience m'a aussi ouvert à la poésie qui se dégage de cette musique, cette impression d'infini. Et pendant que j'étais là-bas, je me disais « quelle est la musique occidentale que j'aimerais le plus écouter maintenant» et je pensais aux grands classiques. Un seul émergeait: Mozart qui est peutêtre le plus mélodique et le plus rythmicien des classiques. Et j'ai trouvé dans les "Scelunding", musiques sacrées de Bali, des accents mozartiens. 


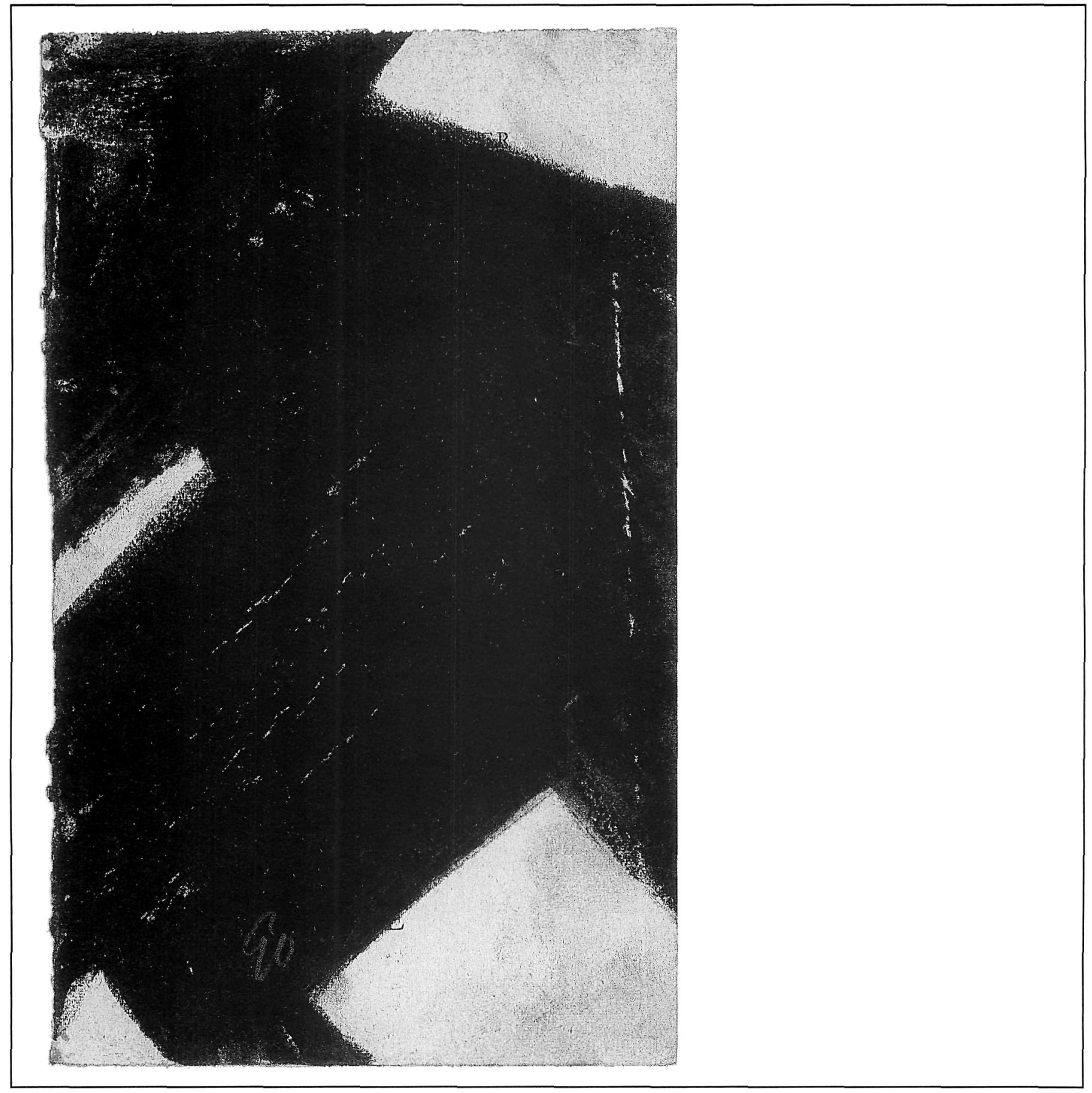

